\title{
Ultrasonically Promoted Synthesis of Ethyl 2-(naphthalen-2-yloxy)acetate in Solid-Liquid Heterogeneous Phase Transfer Catalysis Condition
}

\author{
Pachaiyappan Abimannan, Venugopal Rajendran* \\ Pachaiyappa's College for Men, Kanchipuram, Tamil Nadu, 631 501, India
}

Received: $4^{\text {th }}$ November 2015; Revised: $13^{\text {rd }}$ January 2016; Accepted: $16^{\text {th }}$ January 2016

\begin{abstract}
In this paper, the synthesis of ethyl 2-(naphthalen-2-yloxy)acetate from $\beta$-naphthol and ethyl 2bromoacetate under ultrasound and catalyzed by quaternary ammonium salt in solid-liquid heterogeneous condition was described. Trace amount of water play a major role in this solid-liquid reaction. The reaction follows pseudo first order rate law. The apparent rate constant of the organic phase reaction was obtained form the experimental data. The combination of small amount of tetrabutylammonium bromide (TBAB) and ultrasound $\left(k_{\text {app }}=25.22 \times 10^{-3} \mathrm{~min}^{-1}\right)$ shows several fold enhanced rate of the reaction than the conventional operation ( $k_{\text {app }}=6.42 \times 10^{-3} \mathrm{~min}^{-1}$ for TBAB only). The rate constant increases $(0.05$ to $0.3 \mathrm{~g})$ with increase in the concentration of catalyst (from $k_{a p p}=$ $10.12 \times 10^{-3} \mathrm{~min}^{-1}$ to $k_{a p p}=34.46 \times 10^{-3} \mathrm{~min}^{-1}$ ). The other kinetic effects such as, effect of agitation speed, kind of frequency of ultrasound, kind of various quantity of $\mathrm{K}_{2} \mathrm{CO}_{3}$, quantity of water, temperature, different quaternary ammonium salts, solvents and volume of organic solvents on the conversion of ethyl 2-bromoacetate and apparent rate constant were investigated in detail and rational explanations are provided. Copyright ( $) 2016$ BCREC GROUP. All rights reserved
\end{abstract}

Keywords: phase-transfer catalyst; solid-liquid mode; ethyl 2-bromoacetate; ethyl 2-(naphthalen-2yloxy)acetate; ultrasonication

How to Cite: Abimannan, P., Rajendran, V. (2016). Ultrasonically Promoted Synthesis of Ethyl 2(naphthalen-2-yloxy)acetate in Solid-Liquid Heterogeneous Phase Transfer Catalysis Condition.

Bulletin of Chemical Reaction Engineering \& Catalysis, 11 (3): 273-283

(doi:10.9767/bcrec.11.3.567.273-283)

Permalink/DOI: http://doi.org/10.9767/bcrec.11.3.567.273-283

\section{Introduction}

Phase-transfer catalysis (PTC) [1-3] is an effective technique for conducting heterogeneous reactions where the reagents are located in different phases [4]. In order to reaction take place, the pinch of phase-transfer catalyst was added to the reaction system. The phase-

* Corresponding Author.

E-mail: 1967sssr@gmail.com (V. Rajendran)

Fax No: +91-44-27268824 transfer agent must forming active catalyst with the reactant anion from the aqueous or solid phase and transports it through the interfacial region into the organic phase [5] for an ion-pair extraction of normal phase-transfer catalysis. Undoubtedly, PTC offers many substantial advantages for the practical execution of numerous reactions [6]. PTC technology is now used in the manufacture of an extremely wide variety of chemicals such as polymers, petrochemicals, pharmaceuticals, agrochemicals and other commodities, specialty and fine 
chemicals. According to reaction medium, the heterogeneous phase-transfer catalysis reactions are mainly classified into two categories as solid-liquid PTC (SL-PTC) and liquid-liquid PTC (LL-PTC).

Phase-transfer catalysis offers several advantages like high reaction rate, high yield, high selectivity towards desired product, low energy requirement and operates at milder reaction condition [7]. Among the several PTCs are available, quaternary ammonium salts are the one which is frequently used by many researchers. In recent days, the application of ultrasound in organic synthesis has been enhanced the reaction because of shorter reaction time, increased yield and selectivity of product and energy consumption, etc. [8]. Now researchers are more interested to attempt the reaction with the combination of ultrasound and PTC carried in immiscible heterogeneous reaction under mild and environmentally benign methodology to obtain maximum yield or conversion [9-14].

Sonochemistry, the chemistry associated with ultrasound which is governed by parameters like amplitude and frequency of an applied sound field, temperature, surface tension, vapour pressure, gas content and nuclei density of the solution as well as vessel and probe geometry [15]. Applications for sonochemistry can be found in many areas, but sonochemical processes are most widely developed for heterogeneous reactions [16]. There are two types of effects mediated by ultrasound: chemical and physical. A specific effect is the asymmetric collapse near a solid surface, which forms microjets. These effects of ultrasound were very effective in cleaning and also responsible for rate acceleration in multiphasic reactions, since surface cleaning and erosion lead to improved mass transport.

The product is an ether-ester which is very easily hydrolyzed in alkaline solutions [17]. By applying the SL-PTC, this hydrolysis side reaction can be prevented. The ethyl 2-(naphthalen2 -yloxy)acetate was the starting material which is transformed to several products with different reactants, in which most of products have antimicrobial activity [18-20].

The main objective of this work is to provide the simple and efficient way to synthesize the ethyl 2-(naphthalen-2-yloxy)acetate which is synthetically useful compound under environmentally benign methods like ultrasound and PTC, in solid-liquid heterogeneous condition. The kinetic aspects on the synthesis of ethyl 2(naphthalen-2-yloxy)acetate such as the effects of agitation speed, kind of frequency of ultrasound, kind of various quantity of $\mathrm{K}_{2} \mathrm{CO}_{3}$, quantity of water, temperature, quantity of TBAB, quaternary ammonium salts, solvents and volume of organic solvents were well studied in detail and proposed suitable mechanism for this reaction.

\section{Experimental}

\subsection{Catalysts, chemicals and solvents}

All the reagents, including, B-naphthol (Merck, 98\%), ethyl 2-bromoactate (Avra synthesis Pvt Lt, Hyderabad, India. 97\%), biphenyl (Merck, 99\%), tetra-nbutylammonium iodide (TBAI), tetra-nbutylammonium bromide (TBAB), tetra-nbutylammonium hydrogen sulfate (TBAHS), tetra-n-butylphosphonium bromide (TBPB) and tetra-n-butylammonium chloride (TBAC) were obtained from Avra, Merck, SD Fine chemicals. Potassium carbonate, toluene, chlorobenzene, chloroform, o-dichlorobenzene, n-hexane and other reagents for synthesis were guaranteed grade (GR) chemicals and were used without further purification.

\subsection{Instrumentation}

${ }^{1} \mathrm{H}$ NMR was recorded on a Bruker $300 \mathrm{MHz}$ and ${ }^{13} \mathrm{C}$ spectra were recorded on $75 \mathrm{MHz}$ respectively using TMS as an internal standard. Gas chromatography was carried out using a GC-Varian 3700 model. Ultrasonic water bath was obtained from Equitron, Media Instrument Manufacturing Company, Chennai, India-600 004.

\subsection{Ultrasonic process equipment}

Ultrasonic energy is transmitted to the process vessel through the liquid medium, usually water in the tank. For safety purpose, the sonochemical reactor consisted of two layers stainless steel body. The sonochemical reactor configuration used in the present work is basically an ultrasonic bath. The internal dimension of the ultrasonic cleaner tank is $48 \times 28 \times 20 \mathrm{~cm}$ with liquid holding capacity of 5 liters. Two types of frequencies of ultrasound were used in these experiments, which are 28 $\mathrm{kHz}$ and $40 \mathrm{kHz}$ with each output as $300 \mathrm{~W}$. Both ultrasounds separately produces through a flat transducer mounted at the bottom of the sonicator. The reactor was a $250 \mathrm{~mL}$ threenecked Pyrex round-bottom flask. This reaction vessel was supported at the centre of the ultrasonic cleaning bath $2 \mathrm{~cm}$ above from the 
position of the transducer to get the maximum ultrasound energy. All the experimental parameters were done at $40 \mathrm{kHz}$ with output power of $300 \mathrm{~W}$.

\subsection{Kinetics of synthesis of ethyl 2- (naphthalen-2-yloxy)acetate}

The reaction was conducted on a $250 \mathrm{~mL}$ three-necked Pyrex round-bottom flask this permits agitating the solution, inserting the water condenser to recover organic reactant and taking samples and feeding the reactants. This reaction vessel was supported at the centre of the sonicator. Known quantities of chlorobenzene $(30 \mathrm{~mL})$, dried potassium carbonate $(2.5 \mathrm{~g}$ in $0.5 \mathrm{~mL}$ water) and $0.2 \mathrm{~g}$ biphenyl (IS-internal standard) were introduced into the reactor. Then, $6 \mathrm{~g}$ of $\beta$ naphthol and $1 \mathrm{~g}$ of ethyl 2-bromoacetate, $0.2 \mathrm{~g}$ of TBAB were introduced to the reactor to start the reaction. The reaction mixture was stirred at $600 \mathrm{rpm}$. The phase separation was almost immediate on arresting the stirring process. Samples were collected from the organic layer at regular time intervals and $0.5 \mathrm{~mL}$ of chlorobenzene was added to vials to dilute the solution. The kinetics was followed by estimating the amount of ethyl 2-bromoacetate (limiting reagent) that disappeared and measured by a gas Chromatography (GCVarian 3700 model). The analyzing conditions were as follows: Column, $30 \mathrm{~m} \times 0.525 \mathrm{~mm}$ i.d. capillary column containing $100 \%$ poly(dimethyl siloxanen); injection temperature, $250{ }^{\circ} \mathrm{C}$; FID detector $\left(300{ }^{\circ} \mathrm{C}\right)$. Yields were determined from standard curve using biphenyl as an internal standard.

\subsection{Spectral data of ethyl 2-(naphthalen-2- yloxy)acetate}

After reaction completed, the organic phase solution was concentrated in a vacuum evaporator. Then the remaining organic solution and $30 \mathrm{~mL}$ dichloromethane was poured into the extractor (separating funnel).
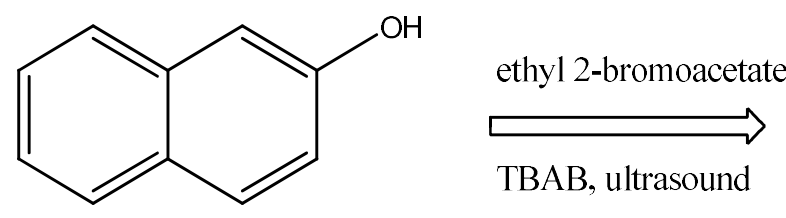

TBAB, ultrasound
The organic solution is extracted five times with deionized water to remove excess aqueous reactant, catalyst and base. The organic solution further concentrated by vacuum evaporator to obtain the colorless liquid. The obtained compound was characterized by NMR techniques (Scheme 1):

${ }^{1} \mathrm{H}$ NMR (300 MHz, $\left.\mathrm{CDCl}_{3}\right)$ : $8.1 .255-1.301(3 \mathrm{H}$, $\left.\mathrm{t},-\mathrm{CH}_{3}\right), 4.208-4.277\left(2 \mathrm{H}, \mathrm{q},-\mathrm{O}-\mathrm{CH}_{2}-\mathrm{CH}_{3}\right)$, $4.574\left(2 \mathrm{H}, \mathrm{s},-\mathrm{O}-\mathrm{CH}_{2}-\mathrm{C}=\mathrm{O}\right), 7.053-7.134(2 \mathrm{H}$, $\mathrm{m}, \mathrm{Ar}-\mathrm{H}), 7.249-7.282(1 \mathrm{H}, \mathrm{t}, \mathrm{Ar}-\mathrm{H})$, 7.354$7.392(1 \mathrm{H}, \quad \mathrm{q}, \quad \mathrm{Ar}-\mathrm{H}), \quad 7.639-7.700(3 \mathrm{H}, \quad \mathrm{m}$, $\mathrm{Ar}-\mathrm{H}) .{ }^{13} \mathrm{C} \mathrm{NMR}\left(75 \mathrm{MHz}, \mathrm{CDCl}_{3}\right)$ : Aliphatic carbons: $\delta 14.06\left(-\mathrm{CH}_{3}\right), 60.51\left(-\mathrm{O}-\mathrm{CH}_{2}-\mathrm{CH}_{3}\right)$, $67.80\left(-\mathrm{CH}_{2}\right.$ Carbon in between ether and keto gruop), 168.64 (Ketone Carbon). Aromatic carbons: $\delta$ 106.72, 119.21, 123.61, 126.43, $126.88,127.81,129.10,129.46,134.87,157.34$, Ketone carbon: $\delta 168.08$.

\section{Reaction Mechanism and Kinetic Model}

The solid-liquid reaction mechanisms are classified into two categories. First one is the non-soluble system (heterogeneous solubilization) introduced by Doraiswamy and Naik [21] and other is soluble system (homogeneous solubilization) introduced by Yadav and Sharma [22]. In this work, $\beta$ naphthol dissolved in the organic solvent with the addition of quaternary ammonium salt $(\mathrm{QBr})$. First, deprotanation of $\mathrm{ArOH}$ occurs in the interface by the $\mathrm{K}_{2} \mathrm{CO}_{3}$ produces the potassium salt of $\beta$-naphthol $\left(\mathrm{ArO}-\mathrm{K}^{+}\right)$and second, anion exchange reaction with $\mathrm{QBr}$ giving the inorganic salt $\mathrm{KBr}$ and active intermediate ArOQ in the interface. Then active intermediate is transported to the organic phase and $\mathrm{KBr}$ is precipitated as solid. In a similar way, Vander Zwan and Hartner [23] and Sasson and Zahalka [24] proved that quaternary ammonium salt can be used to dissolve the solid reactant. Third, the "active intermediate" ArOQ (org) then react with ethyl 2-bromoacetate (EBA) to produce the desired product (Scheme 2) and the catalyst is

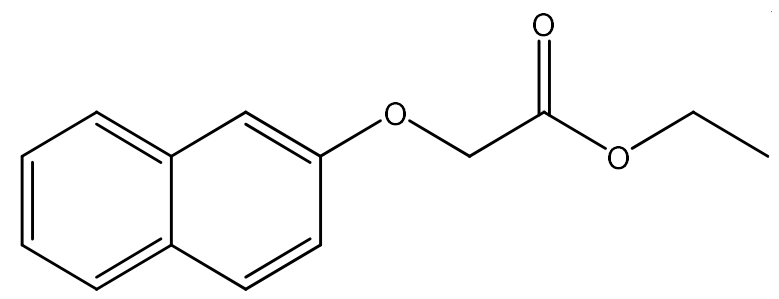

ethyl 2-(naphthalen-2-yloxy)acetate

naphthalen-2-ol

Scheme 1. Synthesis of ethyl 2-(naphthalen-2-yloxy)acetate 
regenerated and the above said cyclic process take place continuously up to the disappearance of ethyl 2-bromoacetate in the bulk organic phase.

\subsection{Definition}

The conversion $(X)$ of ethyl 2-bromoacetate (EBA) is defines in Equation (1):

$$
X=1-\left\{[\mathrm{EBA}]_{0} /[\mathrm{EBA}]_{., \mathrm{o}, \mathrm{i}}\right\}
$$

where $[\mathrm{EBA}]_{0}$ and $[\mathrm{EBA}]_{\mathrm{o}, \mathrm{i}}$ represent the concentration of ethyl 2-bromoacetate at time $(t), t=0$ and $t>0$, respectively.

\subsection{Rate expression}

The rate expression for this reaction may be expressed in Equation (2):

$$
-r_{E B A}=k_{a p p}[\mathrm{EBA}]_{0}
$$

where $k_{a p p}$ is the apparent reaction rate constant.
This reaction is carried out in a batch reactor, so the diminution rate of EBA with time $(t)$ can be expressed in Equation (3):

$$
-d[\mathrm{EBA}]_{0} / d t=-r_{E B A}=k_{a p p}[\mathrm{EBA}]_{\circ}
$$

By integrating Equation (3), we get the following Equation (4):

$$
-\ln \left\{[\mathrm{EBA}]_{0} /[\mathrm{EBA}]_{., \mathrm{o}}\right\}=-\ln (1-X)=k_{\text {app }} t
$$

Using Equation (4), we can get the $k_{\text {app }}$ value experimentally by plotting $-\ln (1-X)$ against time, $(t)$.

\section{Results and Discussion}

\subsection{Effects of stirring speed}

The effect of various stirring speed on the rate of ester-etherification of $\beta$-naphthol with ethyl 2-bromoacetate using TBAB as catalyst was studied in the range of $0-800 \mathrm{rpm}$ in the presence of ultrasound energy $(40 \mathrm{kHz}, 300 \mathrm{~W})$.<smiles>CCOC(=O)COc1ccc2ccccc2c1</smiles>
Organic phase $\uparrow$

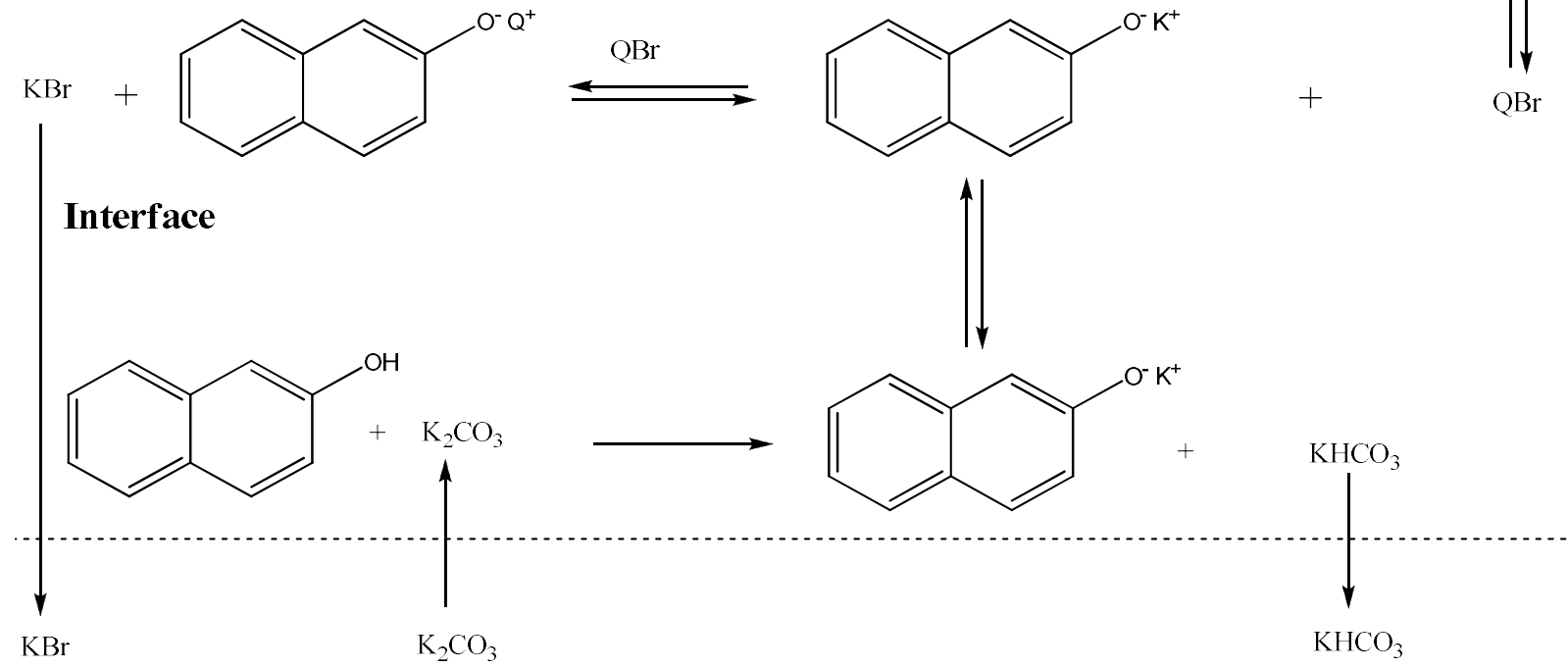

Solid phase

Where, $\mathrm{QBr}=\mathrm{TBAB}$ and 'active intermediate' abbreviated as ArOQ

Scheme 2. Mechanism for the ester-etherification reaction 
From the plots of $-\ln (1-X)$ versus time, the pseudo-first order rate constants were evaluated (Figure 1). As shown in Figure 1, there was a significant increase in the apparent rate constant $\left(k_{a p p}\right)$ from 0 to $300 \mathrm{rpm}$, but it remains constant from 300 to $800 \mathrm{rpm}$. This phenomenon indicates that the influence of the external mass transfer resistance on the reaction beyond $300 \mathrm{rpm}$ is small. Thus, the organic-phase reaction was obviously a ratedetermining step at $300-800 \mathrm{rpm}$. All subsequent reactions were carried at $600 \mathrm{rpm}$ to assess the effect of various factors on the rate of reaction. The reaction was carried out in ultrasound irradiation without stirring, the $k_{a p p}$ is to be $2.13 \times 10^{-3} \mathrm{~min}^{-1}$. The same reaction was carried out in the stirring speed of $600 \mathrm{rpm}$ without ultrasound irradiation, the observed kapp value $\left(k_{a p p}=6.42 \times 10^{-3}, \mathrm{~min}^{-1}\right)$ was almost 3.9 times lesser than in the presence of both ultrasound irradiation $(40 \mathrm{kHz}, 300 \mathrm{~W})$ and stirring $\left(k_{\text {app }}=25.22 \times 10^{-3} \mathrm{~min}^{-1}\right)$.

On the basis of experimental observation, the reaction is still enhanced by ultrasonic irradiation even when the reaction is not agitated by the stirrer. The ultrasonic wave also enhanced the reaction rate due to an increase in the collision rate between the organic-aqueous phase [25]. It is believed that the interfacial area between two phases is affected by both agitation speed and use of ultrasound and which are responsible of the enhancement of the kinetics by harsh mixing, enhancement of mass transfer, especially in solid-liquid systems, high erosion of the solid particles occurs and the surface area is increased [26].

\subsection{Effect of ultrasonic frequencies}

In our experiments, ultrasonic equipment used was described in the experimental Section. The reaction rates at $28 \mathrm{kHz}$ and $40 \mathrm{kHz}$ were compared with same output power of 300 $\mathrm{W}$. The effect of the ultrasonic frequency on the apparent rate constant $\left(k_{a p p}\right)$ is shown in Table 1. At $90 \mathrm{~min}$, without ultrasonic irradiation the reaction rate $\left(k_{a p p}\right)$ is $6.42 \times 10^{-3} \mathrm{~min}^{-1}$. In the presence of ultrasound frequency $28 \mathrm{kHz}$, the reaction rate $\left(k_{a p p}\right)$ is $13.51 \times 10^{-3} \mathrm{~min}^{-1}$. In the presence of ultrasound frequency $40 \mathrm{kHz}$, the reaction rate $25.22 \times 10^{-3} \mathrm{~min}^{-1}$.

From this observed result ultrasonic assisted phase-transfer catalysis significantly improves the reaction rate. The same trend is also observed [27, 28]. In conclusion, the ultrasonic effect enhances the rate several fold with respect to the conventional method (agitation speed at $600 \mathrm{rpm}$ only). Thus, all the experimental parameters were done at $40 \mathrm{kHz}$ with an output power of $300 \mathrm{~W}$.

\subsection{Effect of amount of TBAB loading}

There was very little reaction in the absence of PTC. The concentration of catalyst (TBAB) was varied from 0.05 to $0.3 \mathrm{~g}$, maintaining all other experimental conditions as constant in the presence of ultrasound $(40 \mathrm{kHz}, 300 \mathrm{~W})$.

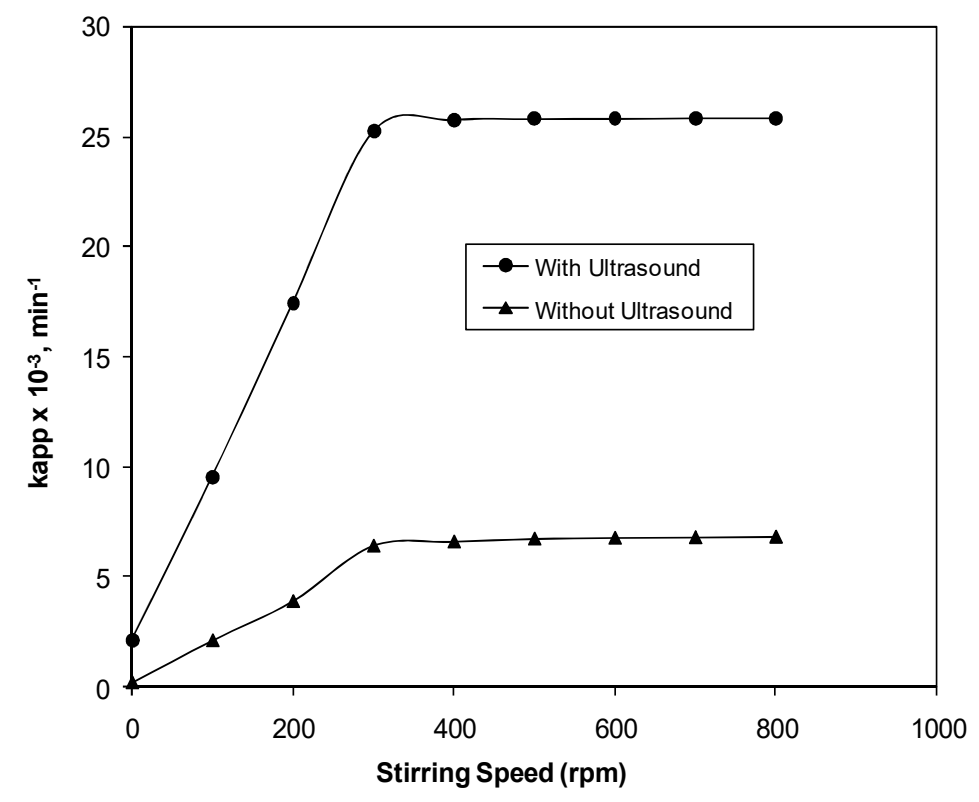

Figure 1. Effect of stirring speed on $k_{a p p}$. Condition: $2.5 \mathrm{~g}$ of $\mathrm{K}_{2} \mathrm{CO}_{3}, 0.5 \mathrm{~mL} \mathrm{H} \mathrm{H}_{2} \mathrm{O}, 0.2 \mathrm{~g}$ of biphenyl (internal standard), $6 \mathrm{~g}$ of $\beta$-naphthol, $1 \mathrm{~g}$ of ethyl 2-bromoacteate, $0.2 \mathrm{~g}$ of TBAB, $30 \mathrm{~mL}$ of chlorobenzene, $50{ }^{\circ} \mathrm{C}, 40 \mathrm{kHz}, 300 \mathrm{~W}$ 
Figure 2 shows the effect of catalyst loading on the conversion of ethyl 2-bromoacetate. As is typical for all PTC reactions, the conversion or rate of the reaction was found to increase with increasing the catalyst loading. The increase in the conversion or rate of the reaction was mainly attributed to the synergistic effect of ultrasound, i.e. induce the surface area, change the size, and morphology of phase-transfer catalyst [29-31]. Further, the opportunity of collision between active intermediate and reactant present in the organic phase is increased by increasing catalyst concentration. Hence, the apparent rate constant values increased with the increase in the amount of catalyst.

\subsection{Effect of the concentration of ethyl 2- bromoacetate}

The kinetic experiments were performed by varying the substrate amount ranging from 0.5-1.5 g, maintain the other reactants such as B-naphthol and potassium carbonate in excess. The kapp values are calculated from the plots of $-\ln (1-X)$ versus time. The data clearly indicates that the $k_{a p p}$ value increases with increasing the amount of ethyl 2-bromoacetate (EBA). This observation due to presence of PTC and higher concentration of substrate (EBA) had co-operatively influence the reaction and thus enhance the more number of contacts between catalyst and substrate (EBA), and hence it is reflected in enhanced $k_{a p p}$ values (Table 2). In addition ultrasound enhance the

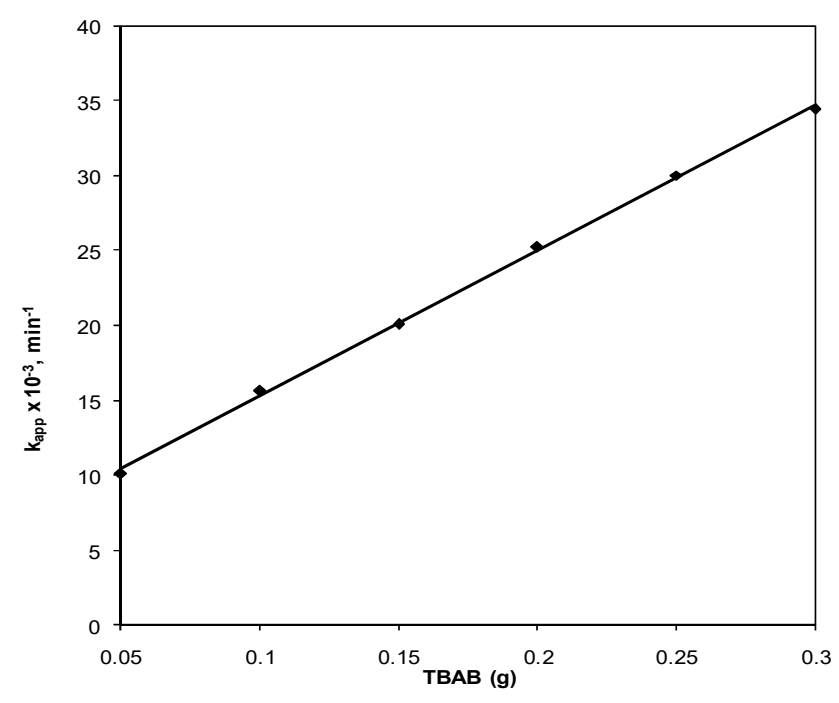

Figure 2. Effect of TBAB amount on $k_{a p p}$. Condition: $2.5 \mathrm{~g}$ of $\mathrm{K}_{2} \mathrm{CO}_{3}, 0.5 \mathrm{~mL} \mathrm{H} \mathrm{H}_{2} \mathrm{O}, 0.2 \mathrm{~g}$ of biphenyl (internal standard), $6 \mathrm{~g}$ of $\beta$-naphthol, $1 \mathrm{~g}$ of ethyl 2-bromoacteate, $600 \mathrm{rpm}, 30 \mathrm{~mL}$ of chlorobenzene, $50{ }^{\circ} \mathrm{C}, 40 \mathrm{kHz}, 300 \mathrm{~W}$ rate of the reaction, it may be due to reduces the surface area between the solid and organic phase, and hence more reactants collide to each other simultaneously we get higher $k_{a p p}$ value [32].

\subsection{Effect of temperature}

The effect of temperature on rate of reaction between $\beta$-naphthol and ethyl 2-bromoacetate was studied for the standard conditions. The temperature was varied from 40 to $80{ }^{\circ} \mathrm{C}$ (Figure 3). The conversion of ethyl 2bromoacetate was observed to increase with increase in reaction temperature along with ultrasonication. This is due to the number of reactant molecules which possess higher activated energy at a higher temperature and thus the ultrasonic wave easily passes through the reactor and increases the collision between the reactants. Generally, the applied ultrasonic frequency induces various degrees of "cavity factor". The cavity factor otherwise called cavitational effect. It is the propagation of ultrasound through a liquid solution in the reactor induces both physical and chemical processes by acoustic cavitation: the formation, growth and adiabatically implosive collapse of bubbles in the liquid solution. The final collapse of the bubbles produces extremely high temperatures $\left(>5000{ }^{\circ} \mathrm{C}\right)$ and pressures $(>100 \mathrm{MPa})$, which accelerated the reaction. The Arrhenius plot was made to determine the energy of activation as $9.99 \mathrm{kcal}^{\mathrm{mol}}{ }^{-1}$ (Figure 6). This value also demonstrates that the reaction is kinetically controlled and an indicative of the interfacial mechanism [33, 34].

\subsection{Effect of organic solvents}

According to solid-liquid PTC reaction systems, intrinsic reactions including the rate con-

Table 1. Effect of ultrasound frequencies on the reaction rate: $2.5 \mathrm{~g}$ of $\mathrm{K}_{2} \mathrm{CO}_{3}$, in $0.5 \mathrm{~mL} \mathrm{H}_{2} \mathrm{O}, 0.2$ $\mathrm{g}$ of biphenyl (internal standard), $6 \mathrm{~g}$ of $\beta$ naphthol, $1 \mathrm{~g}$ of ethyl 2-bromoacteate, $0.2 \mathrm{~g}$ of TBAB, $30 \mathrm{~mL}$ of chlorobenzene, $600 \mathrm{rpm}, 50{ }^{\circ} \mathrm{C}$

\begin{tabular}{cc}
\hline $\begin{array}{c}\text { Ultrasonic frequencies } \\
(\mathrm{kHz})\end{array}$ & $k_{\text {app }} \times 10^{3}, \mathrm{~min}^{-1}$ \\
\hline 0 & 6.42 \\
28 & 13.51 \\
40 & 25.22 \\
\hline
\end{tabular}


stants and the rate are highly affected by the organic solvents. Various solvents have different reaction rates. In this work, five organic solvents were applied to investigate the effect of their polarities and dielectric constants $(\varepsilon)$ on the S-L PTC and ultrasonication system. As in Table 3, the order of reactivities of these five solvents is: o-dichlorobenzene $>$ chlorobenzene $>$ chloroform $>$ toluene $>$ hexane. It was clearly found that the apparent rate constant increased with the dielectric constant of the solvents but did not increase with the polarity. In order to enhance the apparent rate constant, using a high dielectric constant solvent is favorable for the reaction. In addition, the degradation of any organic solvent was not observed during or after the reaction. The results are also shown in Table 3. It was clearly found that the apparent rate constant increases with the dielectric constant of the solvents but does not increase with the polarity.

\subsection{Effect of volume of chlorobenzene}

To study the volume of chlorobenzene on the rate of the reaction, the volume was varied from 30-70 $\mathrm{mL}$ under sonocatalyzed condition. The conversion or the reaction rate is directly proportional to the concentration of the reactants in organic phase in 90 min of reaction (Table 4). This indicates that a low (diluted) concentration of reactant present in the organic phase, active catalyst ArOQ(org) is decreased with the increase in the volume of chlorobenzene. Hence, the probability of collision between the active catalyst ArOQ(org) and the reactant at larger volume of chlorobenzene was not significant. In order to enhance the apparent rate constant, small

Table 2. Effect of amount of ethyl 2bromoacetate (EBA): $2.5 \mathrm{~g}$ of $\mathrm{K}_{2} \mathrm{CO}_{3}, 0.5 \mathrm{~mL}$ $\mathrm{H}_{2} \mathrm{O}, 0.2 \mathrm{~g}$ of biphenyl (internal standard), $6 \mathrm{~g}$ of $\beta$-naphthol, $0.2 \mathrm{~g}$ of TBAB, $30 \mathrm{~mL}$ of chlorobenzene, $600 \mathrm{rpm}, 50^{\circ} \mathrm{C}, 40 \mathrm{kHz}, 300 \mathrm{~W}$

\begin{tabular}{cc}
\hline $\begin{array}{c}\text { Ethyl 2-bromoacetate } \\
\text { (EBA), g }\end{array}$ & $k_{a p p} \times 10^{3}, \mathrm{~min}^{-1}$ \\
\hline 0.5 & 15.38 \\
0.75 & 19.621 \\
1 & 25.22 \\
1.25 & 29.60 \\
1.5 & 33.08 \\
\hline
\end{tabular}

volume of chlorobenzene was favorable for the reaction (Table 4).

\subsection{Effect of different phase-transfer catalysts}

Five different phase-transfer catalysts were employed to explore their efficacy for this reaction. The catalysts tested were tetra-nbutylammonium iodide (TBAI), tetra-nbutylammonium bromide (TBAB), tetra-nbutylammonium hydrogen sulfate (TBAHS), tetra-n-butylphosphonium bromide (TBPB) and tetra-n-butylammonium chloride (TBAC). The results and the corresponding rate constants are shown in Table 5. From Table 5, it is clear that both TBAB and TBPB catalysts show higher activity. The order catalytic reactivity of PTC's are TBPB $>$ TBAB $>$ TBAI approximately equal to TBAHS $>$ TBAC [35, 36]. This indicates that a more lipophilic quaternary cation more easily solvates the solid reactant anion, thus a faster initial reaction rate was obtained. Moreover, the deactivation of TBAI catalyst was greater than that of others. This may be due to larger ionic size of iodide reducing the solubility of ArOQ in chlorobenzene. The production of KI from the reaction of $\mathrm{KBr}$ with TBAI may also retard the formation and concentration of ArOQ in the organic phase, thus reducing the reaction rate.

\subsection{Effect of various potassium carbonate concentrations}

The rate of reaction is tremendously to be affected by a concentration of the alkaline $\mathrm{K}_{2} \mathrm{CO}_{3}$. The rate of ester-etherification of $\beta$ naphthol strongly depends on the strength of the potassium carbonate [37]. Kinetic

Table 3. Influence of organic solvents on the reaction rate: $2.5 \mathrm{~g}$ of $\mathrm{K}_{2} \mathrm{CO}_{3}, 0.5 \mathrm{~mL} \mathrm{H}_{2} \mathrm{O}, 0.2 \mathrm{~g}$ of biphenyl (internal standard), $6 \mathrm{~g}$ of $\beta$-naphthol, $1 \mathrm{~g}$ of ethyl 2-bromoacteate, $0.2 \mathrm{~g}$ of TBAB, $30 \mathrm{~mL}$ of solvents, $600 \mathrm{rpm}, 50{ }^{\circ} \mathrm{C}, 40 \mathrm{kHz}, 300 \mathrm{~W}$

\begin{tabular}{ccc}
\hline Solvents & $\begin{array}{c}\text { Dielectric } \\
\text { constant } \\
\left(\varepsilon^{\mathrm{a}}\right)\end{array}$ & $\begin{array}{c}k_{\text {app }} \times 10^{3} \\
\left(\mathrm{~min}^{-1}\right)\end{array}$ \\
\hline Chlorobenzene & 5.6 & 25.22 \\
O-dichlorobenzene & 9.93 & 28.24 \\
Toluene & 2.4 & 17.12 \\
Hexane & 1.89 & 12.52 \\
Chloroform & 4.8 & 22.13 \\
\hline
\end{tabular}


experiments were carried out by employing 0 to $2.5 \mathrm{~g}$ of $\mathrm{K}_{2} \mathrm{CO}_{3}(0.5 \mathrm{~mL}$ water constant) under otherwise similar reaction conditions. The conversion or rate of reaction was tremendously increased with increasing in basicity (Figure 4). The main reasons are on increasing the alkaline concentration, the amount of production of anion ( $\mathrm{ArO}-$ ) is increased and distribution of active catalyst (ArOQ) is increased. From the Figure 4, the conversion is increased linearly increase in the alkali concentration. The water has a subtle influence on the basicity of $\mathrm{K}_{2} \mathrm{CO}_{3}$ and the hydration of the ion-pair. In order to increase the apparent rate constant $\left(k_{a p p}\right)$, it is favorable

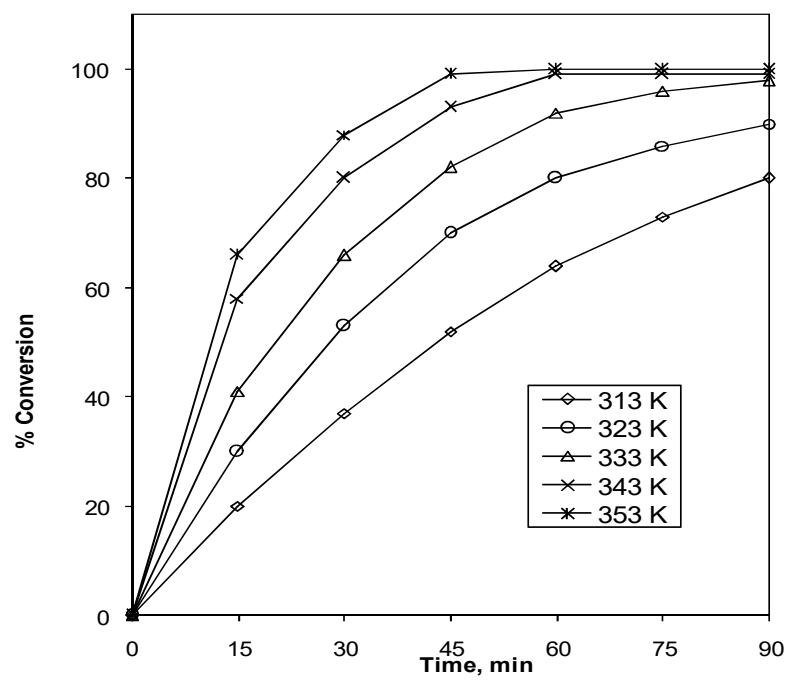

Figure 3. Effect of temperature on conversion. Condition: $2.5 \mathrm{~g}$ of $\mathrm{K}_{2} \mathrm{CO}_{3}, 0.5 \mathrm{~mL} \mathrm{H} \mathrm{H}_{2} \mathrm{O}, 0.2 \mathrm{~g}$ of biphenyl (internal standard), $6 \mathrm{~g}$ of $\beta$-naphthol, $1 \mathrm{~g}$ of ethyl 2-bromoacteate, $0.2 \mathrm{~g}$ of TBAB, 30 $\mathrm{mL}$ of chlorobenzene, $600 \mathrm{rpm}, 40 \mathrm{kHz}, 300 \mathrm{~W}$

Table 4. Effect of volume of chlorobenzene on the rate of reaction: $2.5 \mathrm{~g}$ of $\mathrm{K}_{2} \mathrm{CO}_{3}, 0.5 \mathrm{~mL} \mathrm{H} \mathrm{H}_{2} \mathrm{O}$, $0.2 \mathrm{~g}$ of biphenyl (internal standard), $6 \mathrm{~g}$ of $\mathrm{B}$ naphthol, $1 \mathrm{~g}$ of ethyl 2-bromoacteate, $0.2 \mathrm{~g}$ of TBAB, $600 \mathrm{rpm}, 50{ }^{\circ} \mathrm{C}, 40 \mathrm{kHz}, 300 \mathrm{~W}$

\begin{tabular}{cc}
\hline $\begin{array}{c}\text { Volume of } \\
\text { chlorobenzene }(\mathrm{mL})\end{array}$ & $k_{\text {app }} \times 10^{3}, \mathrm{~min}^{-1}$ \\
\hline 30 & 25.22 \\
40 & 23.04 \\
50 & 21.17 \\
60 & 20.07 \\
70 & 18.57 \\
\hline
\end{tabular}

for the reaction to use less water or be in an anhydrous condition. Thus, that is the reason why the reaction was carried out in a solidliquid solution in this work [38, 39].

\subsection{Effect of water}

In past efforts for solid-liquid phasetransfer-catalyzed systems, additions of water were generally required small quantity or no addition of water is required when quaternary ammonium salts as the catalysts were used. However, in order to investigate the effect of water on the present system, different amounts of water were used and the results are shown in Figure 5. On adding $0-2 \mathrm{~mL}$ of water, the

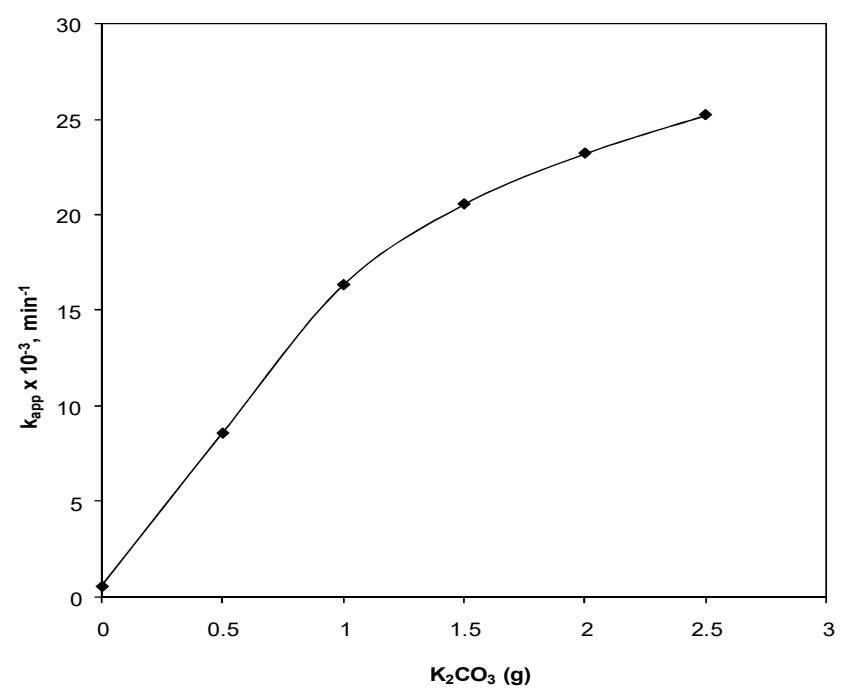

Figure 4. Effect of concentration of potassium carbonate. Condition: $0.5 \mathrm{~mL} \mathrm{H} \mathrm{H}_{2} \mathrm{O}, 0.2 \mathrm{~g}$ of biphenyl (internal standard), $6 \mathrm{~g}$ of $\beta$-naphthol, $1 \mathrm{~g}$ of ethyl 2-bromoacteate, $0.2 \mathrm{~g}$ of TBAB, $30 \mathrm{~mL}$ of chlorobenzene, $50^{\circ} \mathrm{C}, 600 \mathrm{rpm}, 40 \mathrm{kHz}, 300 \mathrm{~W}$

Table 5. Effect of various PTC's on the rate of reaction: $2.5 \mathrm{~g}$ of $\mathrm{K}_{2} \mathrm{CO}_{3}, 0.5 \mathrm{~mL} \mathrm{H} \mathrm{H}_{2} \mathrm{O}, 0.2 \mathrm{~g}$ of biphenyl (internal standard), $6 \mathrm{~g}$ of $\beta$-naphthol, $1 \mathrm{~g}$ of ethyl 2-bromoacteate, $0.2 \mathrm{~g}$ of PTC, $30 \mathrm{~mL}$ of chlorobenzene, $600 \mathrm{rpm}, 50^{\circ} \mathrm{C}, 40 \mathrm{kHz}, 300 \mathrm{~W}$

\begin{tabular}{cc}
\hline PTCs $(\mathrm{g})$ & $k_{a p p} \times 10^{3}, \mathrm{~min}^{-1}$ \\
\hline TBPB & 26.42 \\
TBAB & 25.22 \\
TBAI & 20.87 \\
TBAHS & 20.67 \\
TBAC & 16.13 \\
\hline
\end{tabular}


conversions were observed to decrease. If much more water was added to the system, the overall reactions were no longer of the solidliquid phase type [40]. In solid-liquid system, the addition of small amount of water can be useful in forming the catalytic intermediate for conducting intrinsic reactions.

\section{Conclusions}

In conclusion, the synthesis of ethyl 2(naphthalen-2-yloxy)acetate in solid-liqiud heterogeneous condition under tetra-nbutylammonium bromide and ultrasonication was reported. The enhanced rate of reaction was obtained under sonication and PTC. The apparent reaction rates were observed to obey the pseudo-first order kinetics. The reaction mechanism and the apparent rate constants were obtained from the experimental results. The apparent rate constants are found to be directly dependent on each kinetic variables, viz., concentration of PTC, amount of $\mathrm{K}_{2} \mathrm{CO}_{3}$, ultrasonic frequencies, stirring speed, concentration of ethyl 2-bromoacetate and temperature. However it decreases with increase in the volume of water and volume of chlorobenzene. Energy of activation was calculated from the Arrhenius plot.

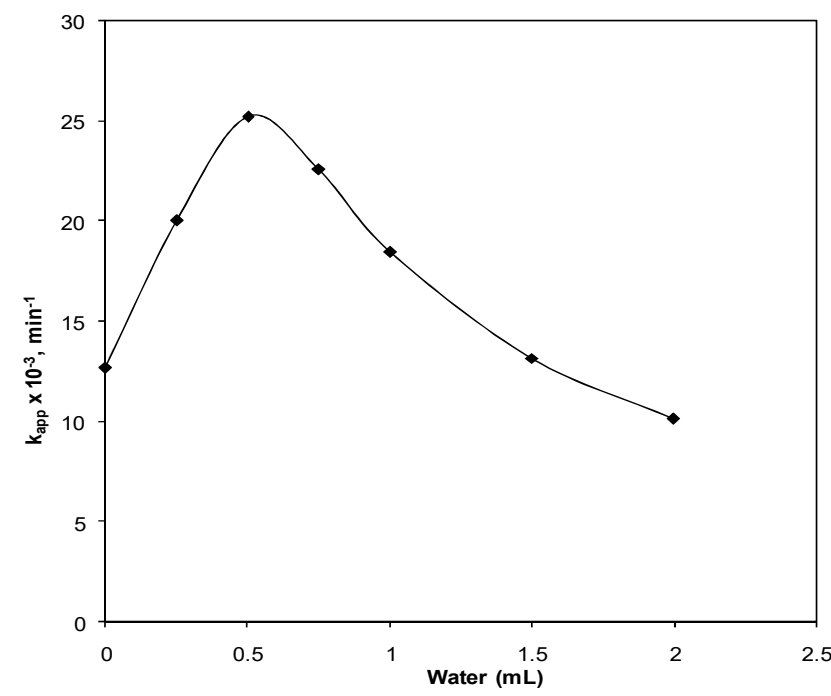

Figure 5. Effect of volume of water on $k_{a p p}$. Condition: $2.5 \mathrm{~g}$ of $\mathrm{K}_{2} \mathrm{CO}_{3}, 0.2 \mathrm{~g}$ of biphenyl (internal standard), $6 \mathrm{~g}$ of $\beta$-naphthol, $1 \mathrm{~g}$ of ethyl 2bromoacteate, $0.2 \mathrm{~g}$ of TBAB, $30 \mathrm{~mL}$ of chlorobenzene, $50{ }^{\circ} \mathrm{C}, 600 \mathrm{rpm}, 40 \mathrm{kHz}, 300 \mathrm{~W}$

\section{Acknowledgement}

The authors would like to thank The University Grants Commission, New Delhi, India, for financial support for this research work. We also thank The Pachaiyappa's Trust, Chennai, Tamil Nadu, India-600 030, for their grant permission to do this research work.

\section{References}

[1] Starks, C.M., Liotta, C.L., Halpern, M.E. (1994). Phase-Transfer Catalysis: Fundamentals, Applications, and Industrial Perspectives, Chapman and Hall Publications, New York, U.S.A.

[2] Weber, W.P., Gokel, G.W. (1997). Phase Transfer Catalysis in Organic Syntheses, Springer Verlag, New York, U.S.A.

[3] Dehmlow, E.V., Dehmlow, S.S. (1993). Phase Transfer Catalysis, 3rd ed., VCH, New York, U.S.A.

[4] Menger, F.M. (1972). Reactivity of organic molecules at phase boundaries. Chem. Soc. Rev. 1: 229-240.

[5] Sasson, Y., Neumann, R. (1997). Handbook of Phase Transfer Catalysis, Blackie Academic and Professional (Chapman \& Hall), London.

[6] Makosza, M., Wawrzyniewicz, M. (1969). Reaction of organic anions XXIV catalytic method for preparation of dichlorocyclopropane derivatives in aqueous medium. Tetrahedron Lett. 53: 4659-4662.

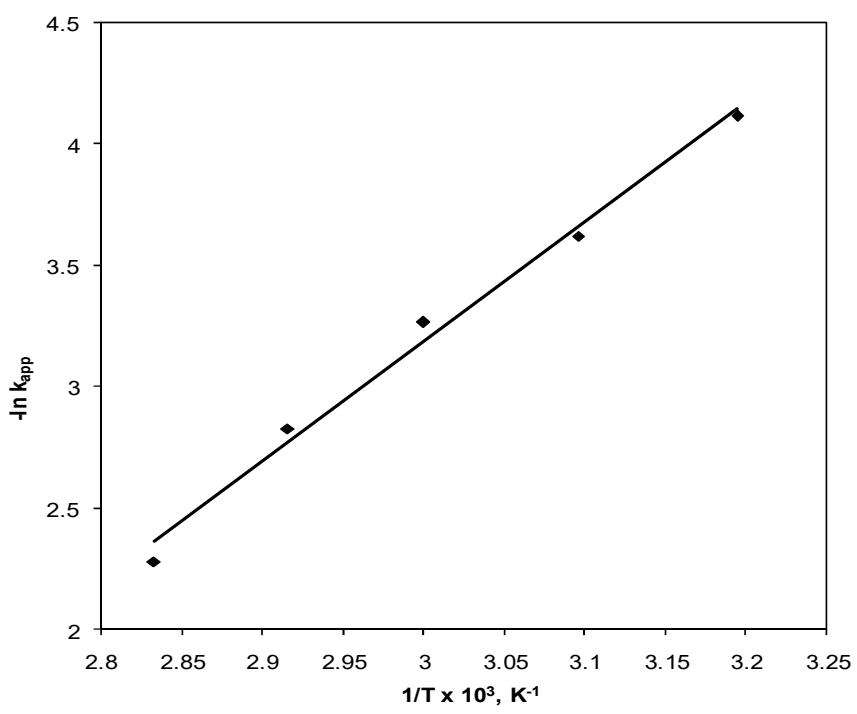

Figure 6. Arrhenius plot. Conditions: $2.5 \mathrm{~g}$ of $\mathrm{K}_{2} \mathrm{CO}_{3}, 0.5 \mathrm{~mL} \mathrm{H}_{2} \mathrm{O}, 0.2 \mathrm{~g}$ of biphenyl (internal standard), $6 \mathrm{~g}$ of $\beta$-naphthol, $1 \mathrm{~g}$ of ethyl 2 bromoacteate, $0.2 \mathrm{~g}$ of TBAB, $30 \mathrm{~mL}$ of chlorobenzene, $600 \mathrm{rpm}, 40 \mathrm{kHz}, 300 \mathrm{~W}$ 
[7] Bijudas, K., Bashpa, P., Bibin, V.P., Nair, L., Priya, A.P., Aswathy, M., Krishnendu, C., Lisha, P. (2015). Bull. Chem. React. Eng. Catal. 10 (1): 38-42.

(doi: 10.9767/bcrec.10.1.7189.38-42)

[8] Mason T.J. (1997). Ultrasound in synthetic organic chemistry. Chem. Soc. Rev., 26: 443451.

[9] Wang, M.L., Rajendran, V. (2006). A kinetic study of thioether synthesis under influence of ultrasound assisted phase-transfer catalysis. J. Mol. Catal. A: Chem. 244: 237-243.

[10] Wang, M.L., Rajendran, V. (2007). Ultrasound assisted phase-transfer catalytic epoxidation of 1,7-octadiene - a kinetic study. Ultrason. Sonochem., 14: 46-54.

[11] Li, J.T., Li, X.L. (2007). An efficient and practical synthesis of methylene dioximes by combination of ultrasound and phase transfer catalyst. Ultrason. Sonochem., 14: 677-679.

[12] Nandurkar, N.S., Bhanushali, M.J., Jagtap, S.R., Bhanage, B.M. (2007). Ultrasound promoted regioselective nitration of phenols using dilute nitric acid in the presence of phase transfer catalyst. Ultrason. Sonochem. 14: 4145.

[13] Yang, H.M., Peng, G.Y. (2010). Ultrasoundassisted third-liquid phase-transfer catalyzed esterification of sodium salicylate in a continuous two-phase flow reactor. Ultrason. Sonochem. 17: 239-245.

[14] Wang, M.L., Chen, C.J. (2010). Kinetic Study of Synthesizing 1-(3-Phenylpropyl) pyrrolidine-2,5-dione under Solid-Liquid PhaseTransfer Catalytic Conditions Assisted by Ultrasonic Irradiation. Org. Process. Res. Dev. 14: 737-745.

[15] Mason, T.J., Lorimer, J.P. (1998). Sonochemistry: Theory, applications and uses of ultrasound in chemistry, Ellis Horwood Limited.

[16] Lan, J.K. (1995). Hydrolysis and substitution reactions of halo-ester, MSc Thesis, National Tsing-Hua University, Taiwan.

[17] Rokade, Y., Dongare, N. (2010). Synthesis and antimicrobial activity of some azetidinone derivatives with the B-naphthol. Rasayan J. Chem, 3: 641-645.

[18] Bhaumik, A., Upendhar, M., Soundarya, D., Sravan Kumar, P., Manogna, Ch. (2013). Synthesis, characterization and evaluation for anti-arthritic activity of some novel 4thiazolidinone derivatives. Int. Res J Pharm. App Sci. 3 (5): 88-93.

[19] Muhammad, S. A., Nadeem, H., Sadiq, A. (2014). Computational drug designing against salmonella typhi: a causative agent of typhoid Int. J. Pharm. 4(1): 252- 255.
[20] Bhaumik, A., Chandra, M. A., Saha, S., Mastanaiah, J., Visalakshi, T. (2014). Synthesis, characterization and evaluation of anticonvulsant activity of some novel 4thiazolidinone derivatives. Sch. Acad. J. Pharm. 3(2): 128-132.

[21] Naik, S.D., Doraiswamy, L.K. (1997). Mathematical model of solid-liquid phasetransfer Catalysis. Chem. Eng. Sci. 52: 45334546.

[22] Yadav, G.D., Sharma, M.M. (1981). Kinetics of benzyl chloride with sodium acetate/benzoate: phase transfer catalysis in solid-liquid system. Ind. Eng. Chem. Proc. Des. Dev. 20: 385-390.

[23] Vander, Z.M.C., Hartner, F.W. (1978). Solidliquid phase-transfer catalysis by a quaternary ammonium salt. A comparison with crown ethers and polyalkylamines. $J$. Org. Chem. 43: 2655-2657.

[24] Sasson Y., Zahalka, H.A. (1983). Catalyst poisoning phenomenon in phase transfer catalysis: effect of aqueous phase concentration. J. Chem. Soc., Chem. Commun. 1347-1349.

[25] Torok, B., Balazsik, K., Felfoldi, K., Bartok, M. (2001). Asymmetric reaction in Sonochemistry. Ultrason. Sonochem. 8: 191200.

[26] Guilet, R., Berlan, J., Louisnared, O., Schwartzentruber, J. (1998). Influence of ultrasound power on the alkylation of phenylacetonitrile under solid-liquid phase transfer catalysis conditions. Ultrason. Sonochem. 5: 21-25.

[27] Vivekanand, P. A., Wang, M. L. (2011). Sonocatalyzed synthesis of 2phenylvaleronitrile under controlled reaction conditions - A kinetic study. Ultrason. Sonochem. 18: 1241-1248.

[28] Abimannan, P., Selvaraj, V., Rajendran, V. (2015). Sonication effect on the reaction of 4bromo-1-methylbenzene with sodium sulfide in liquid-liquid multi-site phase-transfer catalysis condition - Kinetic study. Ultrason. Sonochem. 23: 156-164.

[29] Wang, M.L., Rajendran, V. (2007). Ethoxylation of p-chloronitrobenzene using phase-transfer catalysts by ultrasound irradiation - A kinetic study. Ultrason. Sonochem. 14: 368-374.

[30] Wang, M.L., Rajendran, V. (2007). Kinetics for dichlorocyclopropanation of 1,7-octadiene under the influence of ultrasound assisted phase-transfer catalysis condition. J. Mol. Catal. A: Chem. 273: 5-13. 
[31] Rajendran, V., Wang, M.L. (2008). Dichlorocarbene addition to allyl phenyl ether under phase-transfer catalysis conditions - a kinetic study. J. Mol. Catal. A: Chem. 288: 2327.

[32] Selvaraj, V., Rajendran, V. (2014). Propargylation of indene-1,3-dione under a new phase-transfer catalyst combined with ultrasonication - A kinetic study. Ultrason. Sonochem. 21: 612-619.

[33] Zhao, Q., Sun, J., Li, J., He, J. (2013). Kinetics and mechanism of HornerWadsworth-Emmons reaction of weakly acidic phosphonate in solid-liquid phasetransfer catalysis system. Catal. Commun. 36: 98-103.

[34] Jeeru, L.R., Pradhan, N.C., Kundu, G. (2015). Reduction of Chloronitrobenzenes by Aqueous Ammonium Sulphide: Triphase Catalysis by Anion Exchange Resin. Indian Chemical Engineer, 58(3): 279-296. DOI: 10.1080/00194506.2015.1044028

[35] Landeros, J.M., Silvestre, H.A., Guadarrama, P. (2013). Synthesis of branched cores by poly-O-alkylation reaction under phase transferconditions. A systematic study. J. Mol. Struct. 1037: 412-419.

[36] Selvaraj, V., Rajendran, V. (2014). Ultrasound assisted the preparation of 1-(4nitrophenyl)imidazole under a new multi-site phase-transfer catalyst - Kinetic study. Ultrason. Sonochem. 21: 620-627.
[37] Albanese, D., Landini, D., Maia, A., Penso, M. (1999). Phase transfer catalysis: some recent applications in organic Synthesis. J. Mol. Catal. A: Chem. 150: 113-131.

[38] Wang, M.L., Chen, C.J. (2008). Kinetic Study of Synthesizing 1-(3-Phenylpropyl)pyrrolidine-2,5-dione under Solid-Liquid Phase-Transfer Catalysis. Org. Process Res. Dev. 12: 748-754.

[39] Kurella, S., Basu, J.K., Sengupta, S. (2015). Study of Solid-Liquid Phase Transfer Catalysed Reaction to Produce P-Nitroanisole Using 18-Crown-6 as Catalyst.. Indian Chemical Engineer, DO I : 10.1080/00194506.2015.1064791.

[40] Zhao, Q., Sun, J., Liu, B., He, J. (2013). Synthesis of stilbene, 1,4-distyrylbenzene and 4,4'-distyrylbiphenyl via Horner-WadsworthEmmons reaction in phase-transfer catalysis System. Dyes and Pigments. 99: 339-347. 